Check for updates

Cite this: RSC Adv., 2018, 8, 37811

Received 24th September 2018 Accepted 26th October 2018

DOI: $10.1039 / c 8 r a 07885 h$

rsc.li/rsc-advances

\section{Polyvinylchloride-derived N, S co-doped carbon as an efficient sulfur host for high-performance $\mathrm{Li}-\mathrm{S}$ batteries $\uparrow$}

\author{
Cejun Hu, ${ }^{a}$ Yingna Chang, ${ }^{a}$ Ruida Chen, ${ }^{a}$ Jijin Yang, ${ }^{a}$ Tianhui Xie, ${ }^{a}$ Zheng Chang, ${ }^{a}$ \\ Guoxin Zhang, (DD ${ }^{* b}$ Wen Liu (iD) ${ }^{* a}$ and Xiaoming Sun (D)
}

\begin{abstract}
The intrinsic polysulfide shuttle in lithium-sulfur (Li-S) batteries have significantly limited their practical applications. Conductive carbon materials with heteroatom doping and rich porosity is the most common strategy for the effective prevention of polysulfide shuttle, but are usually obtained with high costs and tedious procedures. Herein, we managed to obtain highly porous N, S-codoped carbon materials (NS-C) through treating waste plastic of polyvinylchloride (PVC) with $\mathrm{KOH}$. The resulting NS-C was revealed to be highly efficient hosts for sulfur cathode, achieving large reversible capacities of $1205 \mathrm{~mA} \mathrm{~h} \mathrm{~g}^{-1}$ and $836 \mathrm{~mA} \mathrm{~h} \mathrm{~g}^{-1}$ at $0.1 \mathrm{C}$ and $1.0 \mathrm{C}$, respectively, and remaining at $550 \mathrm{~mA} \mathrm{~h} \mathrm{~g}^{-1}$ after 500 cycles at $1 \mathrm{C}$ rate, showing an outstanding cycling stability. The significantly enhanced cycling performance was mainly ascribed to both the hierarchically porous structure and heavy $\mathrm{N}, \mathrm{S}$ co-dopants, which respectively provided physical blocks and chemical affinity for the efficient immobilization of intermediate lithium polysulfides. The results provide an effective paradigm in the surface chemistry and sulfur cathode materials design for high-performance Li-S batteries and a new application for recycled plastic waste.
\end{abstract}

\section{Introduction}

Lithium-sulfur batteries have been regarded as the most promising high-density energy storage devices for the nextgeneration portable electronics, electric vehicles, and grid energy storage, ${ }^{1,2}$ owing to their high theoretical energy density $\left.(2600 \mathrm{~W} \mathrm{~h} \mathrm{~kg})^{-1}\right)^{3,4}$ and abundant reserved sources of sulfur in the Earth's crust. ${ }^{5}$ However, the issues of polysulfide shuttle $^{6-8}$ and low sulfur utilization ${ }^{9}$ have significantly impeded the commercialization of Li-S batteries. Extensive efforts have been employed to ease the abovementioned issues through efficient confinement of soluble polysulfide. $^{10,11}$ Up to now, conductive carbon materials of different kinds (including porous carbon materials $(\mathrm{PCM}),{ }^{12-14}$ graphene ${ }^{15,16}$ and carbon nanotubes ${ }^{17,18}$ ) are among the most commonly applicable hosts for sulfur because of their merits of excellent conductivity, ${ }^{19,20}$ mechanical resilience, ${ }^{10,21}$ and low density, ${ }^{22}$ reaching

\footnotetext{
${ }^{a}$ State Key Laboratory of Chemical Resource Engineering, College of Energy, Beijing Advanced Innovation Center for Soft Matter Science and Engineering, Beijing University of Chemical Technology, Beijing 100029, China. E-mail: wenliu@mail. buct.edu.cn

${ }^{b}$ College of Electrical Engineering and Automation, Shandong University of Science and Technology, Qingdao 266590, China. E-mail: zhanggx@sdust.edu.cn

$\dagger$ Electronic supplementary information (ESI) available: TEM, SEM images, XRD pattern, Raman spectra and pore size distribution, XPS spectrum, and electrochemical data of controlled samples. See DOI: $10.1039 / \mathrm{c} 8 \mathrm{ra} 07885 \mathrm{~h}$
}

satisfactorily high sulfur loading density with reasonably good long-term cycling stability. ${ }^{23}$

The potential of carbon materials (CMs) for pore generation and heteroatom doping further enables their capability of entrapping polysulfides through physical restriction ${ }^{24,25}$ and chemical adsorption, ${ }^{26,27}$ respectively. For instance, CMK-3 with ordered mesopores $(\sim 3.3 \mathrm{~nm})$, when used as a host for sulfur, exhibited high reversible capacity of $1320 \mathrm{~mA} \mathrm{~h} \mathrm{~g}^{-1}$ with good rate and cycling performances. ${ }^{28}$ Additionally, creating polarized interfaces in PCM (such as hollow carbon spheres, ${ }^{29}$ microporous $^{30,31}$ and mesoporous carbons ${ }^{6,32,33}$ ) by introducing heteroatom species have been confirmed to be highly efficient for the immobilization of polysulfides to enhance the comprehensive performance of Li-S batteries. ${ }^{34}$ For example, introducing nitrogen species in 2D PCMs achieved a significant improvement of polysulfide-binding capability. ${ }^{35}$ Yet unfortunately, most of the applicatory PCMs with heavy heteroatom doping and rich porosity demand tedious synthesis procedures ${ }^{31}$ and even high costs, ${ }^{36}$ which severely hinder the practical applications of Li-S batteries. Therefore, it is critical to explore the time-/cost-efficient routes to fabricate carbon materials with a heavy dopant and abundant porosity at a large scale.

Halogen-containing polymers (such as polyvinylchloride (PVC), polyvinyl dichloride (PVDC), polyvinylidene fluoride (PVDF)) represent one sort of widely applicable engineering plastics, which are currently playing important roles in our daily life ranging from healthcare, packaging, and construction materials. ${ }^{24}$ However, 
their excessive applications and extremely high stability have led to huge accumulation in our environment and serious environmental issues regarding safety and pollution. ${ }^{37}$ Recently, our group has developed a facile method to enable the fast defunctionalization and carbonization of PVDF/PVDC under mild conditions ${ }^{38}$ (for example, hand grinding 60 seconds at room temperature). Moreover, in the synthesis, heteroatom species can be in situ introduced into the as-formed carbon lattice by simply adding a hetero-source (such as melamine for $\mathrm{N}$ doping ${ }^{39-41}$ ) before the dehalogenation reaction is initiated. Since PVC is also one type of halogenated polymer and heavily applied and accumulated in human society, converting unwanted PVC wastes into value-added doped PCM holds significant practical value, which may allow us to access the practical carbon recycling and applications of PCMs, especially in $\mathrm{Li}-\mathrm{S}$ batteries.

Hence, N, S-codoped PCMs were synthesized following the previously established dehalogenation strategy, that is, through a two-step method. Briefly, ball milling the mixture of PVC, $\mathrm{KOH}$, and dopant (thiourea as codoping source) at room temperature and annealing under an inert atmosphere afforded the N, S-codoped PCMs. The resulting N, S-codoped PCMs (termed as NS-C), as revealed by TEM, BET, and XPS measurements, possessed rich pores (micropore volume $0.40 \mathrm{~cm}^{3} \mathrm{~g}^{-1}$ ), large specific surface areas (SSA, $\sim 808 \mathrm{~m}^{2} \mathrm{~g}^{-1}$ ), and heavy $\mathrm{N}$, S-loading (6.5 at\% $\mathrm{N}$ and 7.2 at\% $\mathrm{S}$ ). The asobtained NS-C, with reference to non-doped PCM (PC), was examined as a sulfur host for Li-S battery. Remarkably, at a sulfur loading density of $\sim 1.6 \mathrm{mg} \mathrm{cm}^{-2}$, the NS-C/S cathode exhibited a high reversible capacity of $\sim 1230 \mathrm{~mA} \mathrm{~h} \mathrm{~g}^{-1}$ (at $0.1 \mathrm{C}$ ), high rate performance (capacity retention of $\sim 71 \%$ at 1C), and reasonably good cycling performance (capacity loss of $\sim 0.058 \%$ per cycle in 500 cycles). While the non-doped PCM sample showed only $\sim 965 \mathrm{~mA} \mathrm{~h} \mathrm{~g}^{-1}$ at $0.1 \mathrm{C}$, which was about $75 \%$ less than NS-C, confirming the critical role of heteroatom doping in mobilizing polysulfides. Moreover, even at a high mass loading of $\sim 5 \mathrm{mg} \mathrm{cm}^{-2}$, the assembled Li-S cells with NS-C host still demonstrated a very high capacity retention of about $80 \%$ after 200 cycles (at 1C).

\section{Experimental methods}

\subsection{Materials}

PVC was acquired from discarded plastic bags. Thiourea, $\mathrm{KOH}$ of A.R grade and sublimed sulfur (99.99\%) was obtained from Aladdin. DMF and NMP were received from Innochem Chemical Reagents (China). Polyvinylidene fluoride (PVDF) and Super $\mathrm{P}$ were obtained from Hefei Kejing Materials Technology Co. LTD. Electrolytes were purchased from Xiaoyuan Energy Technology Co. LTD (Shanghai). Li foil was bought from China Energy Lithium Co., Ltd. In this experiment, all the chemicals were used without further treatment.

\subsection{Preparation of porous carbon materials and sulfur cathode materials}

N, S-codoped porous carbon material (termed as NS-C) was prepared following the polymer dehalogenation strategy. First,
$1.0 \mathrm{~g}$ PVC was stirred in $10 \mathrm{~mL}$ DMF for $30 \mathrm{~min}$ to obtain a homogenous solution. The PVC/DMF solution was then transferred into a $\mathrm{ZrO}_{2}$ ball mill jar, followed by adding $2.0 \mathrm{~g}$ $\mathrm{KOH}, 1.0 \mathrm{~g}$ thiourea and $10 \mathrm{~mL}$ DMF additionally. The mixture was ball milled at $150 \mathrm{rpm}$ for 2 hours, resulting in a brown slurry. After that, the brown slurry was dried at $60{ }^{\circ} \mathrm{C}$ overnight. The dried precursor was ground in an agate mortar and annealed at $600{ }^{\circ} \mathrm{C}$ under the protection of Ar. The resulting black solid was thoroughly washed by $5 \mathrm{wt} \% \mathrm{HCl}$ solution and deionized water for at least 3 times, dried at $60^{\circ} \mathrm{C}$ overnight and stored for further use. The non-doped PCM was also synthesized as a control sample following the same protocol but without the addition of thiourea.

To load sulfur into PCMs, the as-synthesized NS-C or PC was mixed with sulfur at the mass ratio of $3: 7$, heated at $155^{\circ} \mathrm{C}$ for $12 \mathrm{~h}$ in an autoclave under the protection of inert gas, and the final composite was denoted as NS-C/S and PC/S, respectively.

\subsection{Materials characterization}

SEM (Zeiss SUPRA 55, accelerating voltage at $20 \mathrm{kV}$ ) and HRTEM (JEOL JEM-2100, accelerating voltage at $200 \mathrm{kV}$ ) were used to characterize structure and morphology of the material. X-ray powder diffraction patterns were recorded using an X-ray diffractometer (XRD, Shimadzu XRD-6000, $\mathrm{Cu} \mathrm{K} \alpha$ source, $\lambda=$ $1.5418 \AA$ A). Raman spectra were performed using a HORIBA Jobin Yvon system with a $532 \mathrm{~nm}$ excitation laser. BET measurements were conducted on a Micromeritics Tristar II 3020 instrument. XPS spectra were carried out using a Thermo Electron ESCALAB 250 system. The UV-Vis spectroscopy was obtained by using a UV-2600 spectrophotometer from $750 \mathrm{~nm}$ to

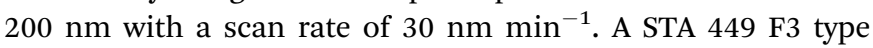
machine (NETZSCH) was used to carry out thermogravimetric (TG) analysis.

\subsection{Preparation of composite sulfur cathodes}

The cathode slurry was first prepared by using $75 \%$ NS-C/S composites, 15\% Super P, and 10\% PVDF powder with $2 \mathrm{~mL}$ $N$-methyl pyrrolidone (NMP). Then the as-made slurry was coated onto Al foil, reaching a mixture loading density of $\sim 3.0 \mathrm{mg} \mathrm{cm}^{-2}$ (S loading of $\sim 1.6 \mathrm{mg} \mathrm{cm}^{-2}$ ). The electrode film on $\mathrm{Al}$ foil was then dried at $60{ }^{\circ} \mathrm{C}$ for $12 \mathrm{~h}$. Meanwhile, an electrode with high sulfur loading of $5.0 \mathrm{mg} \mathrm{cm}^{-2}$ was also prepared to further demonstrate the merits of our NS-C.

\subsection{Electrochemical measurements}

The assembly of coin type (CR 2032) Li-S cells were all conducted in the Ar-protected glovebox. Celgard 2325 membrane and $\mathrm{Li}$ foil (16 $\mathrm{mm}$ in diameter) were used as separator and anode, respectively. The electrolyte/sulfur ratio was around $8 \mu \mathrm{L}$ $\mathrm{mg}^{-1}$. The galvanostatic charge-discharge tests were performed on a Land battery test system (Land CT 2001, Wuhan) in the potential range of 1.7-2.8 V. The cyclic voltammetry (CV) curves were performed at the rate of $0.1 \mathrm{mV} \mathrm{s}^{-1}$ from 1.7 to $2.8 \mathrm{~V}$. Electrochemical impedance spectra (EIS) were recorded on a CHI 660E electrochemical workstation (Ch Instruments, Shanghai) conducted at open circuit voltage with an applied 
sinusoidal excitation voltage of $5 \mathrm{mV}$ in a frequency range from $0.01 \mathrm{~Hz}$ to $100 \mathrm{kHz}$.

\section{Result and discussion}

As schematically shown in Fig. 1A-C, initially, carbonaceous materials were obtained by ball milling raw materials including PVC discarded plastic bags (carbon source), thiourea (N, S source), and $\mathrm{KOH}$ (dechlorination agent) at room temperature (RT, $\sim 25{ }^{\circ} \mathrm{C}$ ), as indicated by the black slurry in Fig. 1B. The dechlorination of PVC occurs soon after exposure to $\mathrm{KOH}$, which was due to the very high reactivity between $\mathrm{KOH}$ and PVC. The on-site defunctionalizing $\mathrm{C}$ sites were highly reactive and capable of coupling any adjacent atoms. During this dechlorination process, thiourea, the $\mathrm{N}, \mathrm{S}$ dopant, could be efficiently incorporated into the dechlorinating sites and eventually reached stable configurations after a prolonged duration of ballmilling and subsequent annealing (Fig. 1C). The precursor products after ball milling were submitted to XRD characterization. Fig. 1D shows the dominant presence of $\mathrm{KCl}$ that is probably obtained through the high reactivity between $\mathrm{KOH}$ and $\mathrm{H} / \mathrm{Cl}$ moieties on the PVC chain, confirming the achievable dechlorination of PVC or even the formation of carbonaceous materials (seen from the dark black color in Fig. 1B). After that, inert annealing was performed on the carbonaceous precursors to recover conductivity for electrochemical applications. Due to the generation of a large amount of volatilizable gases, the annealed product was grafted with rich open pores, as shown in Fig. 1C and S1, $\dagger$ a typical honeycomb-like cellular structure was revealed. To verify the distribution of doping elements, elemental mapping was carried out and shown in Fig. S1C. $\uparrow$ While with no addition of thiourea, minor porosity was seen from the annealed product from PVC and $\mathrm{KOH}$ (Fig. S1B $\dagger$ ). After careful washing, the carbon product with or without $\mathrm{N}, \mathrm{S}$ doping, respectively termed as NS-C and PC, were all revealed to be amorphous carbon materials, as indicated by the broadened (002) diffraction peaks located at $\sim 23^{\circ}$ in the XRD pattern (Fig. 1D and S2A $\dagger$ ). ${ }^{42}$ Raman spectra in Fig. 1E (NS-C) and Fig. $\mathrm{S} 2 \mathrm{~B} \uparrow(\mathrm{PC})$ further confirmed the high carbonization degree

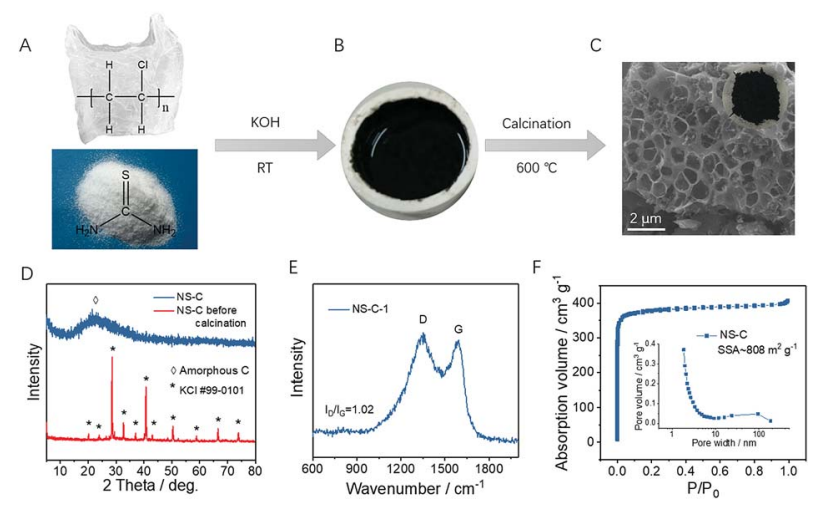

Fig. 1 Fabrication process, morphology characterization and the physical properties of the porous structure materials (NS-C). (A) Row materials. (B) End-product of the NS-C sample. (C) SEM image of NS-C shows a cellular structure. (D) XRD pattern. (E) Raman spectra and (F) pore size distribution of the NS-C samples. of the resulting carbon materials by the distinct presence of the $\mathrm{G}$ band (located at $\sim 1578 \mathrm{~cm}^{-1}$ ) that originated from the $\mathrm{E}_{2 \mathrm{~g}}$ stretching mode of $\mathrm{sp}^{2}$ carbon-carbon bonds. ${ }^{43,44}$ The $\mathrm{D}$ band at $\sim 1350 \mathrm{~cm}^{-1}$, representing the disordered carbon bonding, indicated that the as-prepared carbon materials from the dechlorination of PVC possessed large amount of defects due to the large amount of $\mathrm{N}, \mathrm{S}$ doping, and non-graphitic carbon bonding. ${ }^{45,46}$

NS-C and PC were further submitted to BET measurements. $\mathrm{N}_{2}$ adsorption/desorption isotherms in Fig. $1 \mathrm{~F}$ and S2C $\dagger$ characterized the overwhelming presence of a large amount of micropores by both samples, as indicated by the large absorption volume at low relative pressure. Based on the single-point surface area method, the NS-C sample was calculated to have a very large specific surface area (SSA) of $\sim 808 \mathrm{~m}^{2} \mathrm{~g}^{-1}$ relative to that of $\sim 640 \mathrm{~m}^{2} \mathrm{~g}^{-1}$ for the PC sample. Besides the activation effect of $\mathrm{KOH},{ }^{38}$ the increased SSA of NS-C was possibly obtained by the activation of small volatilizable molecules (such as $\mathrm{CO}_{2}$, $\mathrm{H}_{2} \mathrm{O}$ ). The inset of Fig. 1F shows the pore distribution curve of NS-C, with rich mesoporosity ranging from 2 to $10 \mathrm{~nm}$ and a minor amount of macro-porosity ranging 50 to $100 \mathrm{~nm}$, which could be used for sulfur accommodation. ${ }^{47} \mathrm{X}$-ray photoelectron spectroscopy (XPS) measurements were obtained to investigate the surface chemical composition and functional groups of NS$\mathrm{C}$ and PC. Fig. 2A demonstrates the elemental survey where four main elements were detected: C (1s, $285 \mathrm{eV}), \mathrm{O}(1 \mathrm{~s}, \sim 533$ $\mathrm{eV}), \mathrm{N}(1 \mathrm{~s}, \sim 400.5 \mathrm{eV})$, and $\mathrm{S}(2 \mathrm{p}, \sim 165 \mathrm{eV})$ for NS-C while PC exhibited only $\mathrm{C}$ and $\mathrm{O}$ signals. ${ }^{48}$ As summarized in Fig. $2 \mathrm{~B}$, the incorporated $\mathrm{N}$ and $\mathrm{S}$ contents could reach 6.5 at\% and 7.2 at $\%$, respectively, which could be expected with reasonably good polysulfide-trapping capability. ${ }^{49}$ The $\mathrm{C}$ 1s spectra of NS-C are shown in Fig. S3A, $\dagger$ which can be deconvoluted into three peaks corresponding to three types of $\mathrm{C}-\mathrm{C} / \mathrm{C}=\mathrm{C}, \mathrm{C}-\mathrm{O} / \mathrm{C}-\mathrm{N} / \mathrm{C}-\mathrm{S}$, and $\mathrm{O}-\mathrm{C}=\mathrm{O}$ moieties ${ }^{26}$ Correspondingly, Fig. $2 \mathrm{C}$ and $\mathrm{D}$ showed that
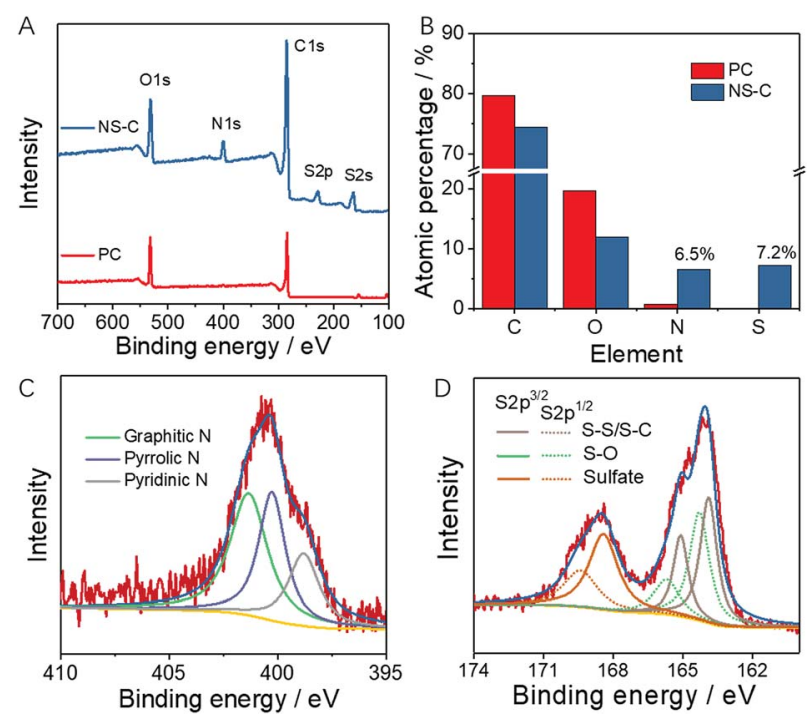

Fig. 2 Surface chemical composition of the plastic waste derived carbons. (A) XPS spectrum of the two samples. (B) Elemental composition of each sample. High resolutions XPS profile of (C) N 1s, and (D) S $2 p$ in the NS-C sample. 
various types of $\mathrm{N}$ and $\mathrm{S}$ species could be identified. Fig. 2C indicated the presence of three main types of $\mathrm{N}$ species: graphitic $\mathrm{N}$, pyrrolic $\mathrm{N}$, and pyridinic $\mathrm{N}$, respectively located at $\sim 401.4 \mathrm{eV}, \sim 400.2 \mathrm{eV}$ and $\sim 398.8 \mathrm{eV} .{ }^{50}$ As shown in Fig. $2 \mathrm{D}$, the $\mathrm{S} 2 \mathrm{p}$ spectra could be deconvoluted into six peaks. The peaks centred at $\sim 163.8 / \sim 165.0 \mathrm{eV}$ corresponded to S-S/S-C species while $\sim 168.3 \mathrm{eV} / \sim 169.5 \mathrm{eV}$ for sulfate species, and $\sim 164.5 /$ $165.7 \mathrm{eV}$ for S-O bonding. ${ }^{\mathbf{4 9}, 51,52}$ According to previous studies, the heteroatom doping, especially $\mathrm{N}$ and $\mathrm{S}$, can significantly alter the electron distribution in carbon lattices and thus enhance their interaction with lithium polysulfides, ${ }^{25,26}$ which may be of great help to prevent the lithium polysulfide (LiPS) shuttle.

The capability of trapping LiPS of NS-C with reference to PC was examined using a simple ex situ adsorption test (Fig. 3A). $5.0 \mathrm{~mL}$ of $2.5 \mathrm{mM} \mathrm{Li}_{2} \mathrm{~S}_{6}$ was dissolved into $5.0 \mathrm{~mL}$ of electrolyte in vials, as shown in the inset of Fig. 3A. Following this, NS-C or $\mathrm{PC}$ was added into the solution and the $\mathrm{Li}_{2} \mathrm{~S}_{6}$ /electrolyte mixture was set as the control. Notably, with the addition of NS-C, the color of the $\mathrm{Li}_{2} \mathrm{~S}_{6} /$ electrolyte mixture changed from dark brown to colorless in 2 hours. In contrast, even with the same amount of PC, the mixture remained brown, suggesting that the heavy doping in NS-C contribute to the efficient trapping of LiPS. UVVis spectroscopy was applied on the supernatant of the $\mathrm{Li}_{2} \mathrm{~S}_{6}$ / electrolyte to measure the absorbance change after the addition of NS-C and PC. As shown in Fig. 3A, the blank $\mathrm{Li}_{2} \mathrm{~S}_{6} /$ electrolyte exhibited strong absorbance in the range of $400-500 \mathrm{~nm} \cdot{ }^{53,54} \mathrm{~A}$ nearly horizontal absorbance curve was achieved by adding NS$\mathrm{C}$ in $\mathrm{Li}_{2} \mathrm{~S}_{6}$ /electrolyte while the PC sample only showed reduced absorbance. The abovementioned findings confirmed that the included heteroatom in the carbon lattices was capable of significantly enhancing the trapping capability of LiPS. ${ }^{33}$ After that, sulfur was loaded in as-made porous carbon materials obtained from PVC to fabricate sulfur cathode materials for $\mathrm{Li}-\mathrm{S}$ batteries. X-ray diffraction (XRD) patterns in Fig. 3B revealed that elemental sulfur was successfully loaded in NS-C and PC. The loading amounts of sulfur in NS-C and PC, as detected by thermogravimetric analysis (TGA), were all approximately 70.5 and $73.8 \mathrm{wt} \%$ (Fig. 3C).

The electrochemical performance of NS-C/S and PC/S cathodes were evaluated in coin-type cells using sulfur composites as cathodes and lithium foil as anode. The mass loading of elemental sulfur was $\sim 1.6 \mathrm{mg} \mathrm{cm}^{-2}$. As shown in Fig. $\mathrm{S} 4, \dagger$ the elemental mapping of $\mathrm{S}$ demonstrated the uniform distribution
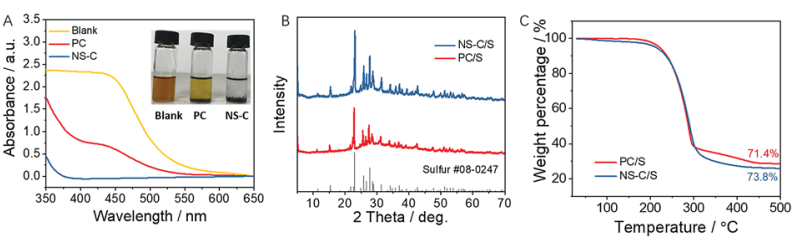

Fig. 3 Lithium polysulfides absorption test. (A) UV-Vis spectra of bare $\mathrm{Li}_{2} \mathrm{~S}_{6}$ solution and after being immersed with PC and NS-C carbons, respectively; the inset picture shows the color change after lithium polysulfides adsorption test, and the blank $\mathrm{Li}_{2} \mathrm{~S}_{6}$ solution was used as a control. (B) XRD pattern after sulfur mixed and (C) thermogravimetric curves of sulfur deposited materials of $\mathrm{PC} / \mathrm{S}$ and $\mathrm{NS}-\mathrm{C} / \mathrm{S}$. of S elements. Cyclic voltammogram (CV) was first scanned between 1.7-2.8 $\mathrm{V}$ with a scan rate of $0.1 \mathrm{mV} \mathrm{s}^{-1} .^{55,56}$ As displayed in Fig. $4 \mathrm{~A}$, at the cathodic scan, the first peak at $\sim 2.28 \mathrm{~V}$ (vs. $\mathrm{Li} / \mathrm{Li}^{+}$) is attributed to the transformation from $\mathrm{S}_{8}$ to the long-chain soluble lithium polysulfide $\left(\mathrm{Li}_{2} \mathrm{~S}_{8}-\mathrm{Li}_{2} \mathrm{~S}_{4}\right){ }^{57}$ The next peak at $\sim 1.95 \mathrm{~V}\left(v s . \mathrm{Li} / \mathrm{Li}^{+}\right)$illustrated the conversion of soluble short-chain lithium polysulfides to the insoluble lithium polysulfides $\left(\mathrm{Li}_{2} \mathrm{~S}_{2}-\mathrm{Li}_{2} \mathrm{~S}\right) .{ }^{58}$ In the anodic scan, two oxidation peaks were located at $\sim 2.35$ and $2.45 \mathrm{~V}$, indicating the delithiation process of lithium sulfide and LiPSs, respectively. ${ }^{59}$ From the second cycle on, the CV curves exhibited highly overlapped forms, implying the outstanding cycling stability of NS-C/S cathode. Although the PC/S cathode also exhibited a similar tendency after the second cycle (Fig. S5 $\dagger \dagger$ ), the NS-C/S electrode possessed a higher peak current density and lower polarization voltage when compared to the $\mathrm{PC} / \mathrm{S}$ cathode, indicating higher reactivity of the NS-C/S electrode and improved redox kinetics of the polysulfide intermediates. ${ }^{60}$ Furthermore, the EIS measurement (Fig. S6 $\dagger$ ) was tested before cycling (charged) with an applied sinusoidal excitation voltage of $5 \mathrm{mV}$ in a frequency range from $0.01 \mathrm{~Hz}$ to $100 \mathrm{kHz}$. The result confirmed that the NS-C/S cathode exhibited much lower charge-transfer resistances than the PC/S cathode, suggesting a better electrolyte infiltration and fast charge transfer capability of the NS-C/S composite, which was probably ascribed to the stronger LiPStrapping capability and less formation of "dead" sulfur. ${ }^{31}$

Fig. 4B displays the discharge/charge profiles of $\mathrm{Li}-\mathrm{S}$ cells with NS-C/S cathodes from $0.1 \mathrm{C}$ to $2 \mathrm{C}$. Initially, the NS-C/S cathode was characterized by a very large capacity of $\sim 1230 \mathrm{~mA} \mathrm{~h} \mathrm{~g}^{-1}$ at $0.1 \mathrm{C}$, suggesting that the heavy $\mathrm{N}$, S dopants not only helped to trap the soluble LiPS but also increased the utilization of sulfur. Meanwhile, the lowest voltage hysteresis was observed on the NS-C/S cathode, which was consistent with the smallest polarization voltage from the CV curves. Furthermore, the NS-C/S cathode still exhibited a large specific capacity of $815 \mathrm{~mA} \mathrm{~h} \mathrm{~g}^{-1}$ at $1 \mathrm{C}$ and $640 \mathrm{~mA} \mathrm{~h} \mathrm{~g}^{-1}$ at high current density
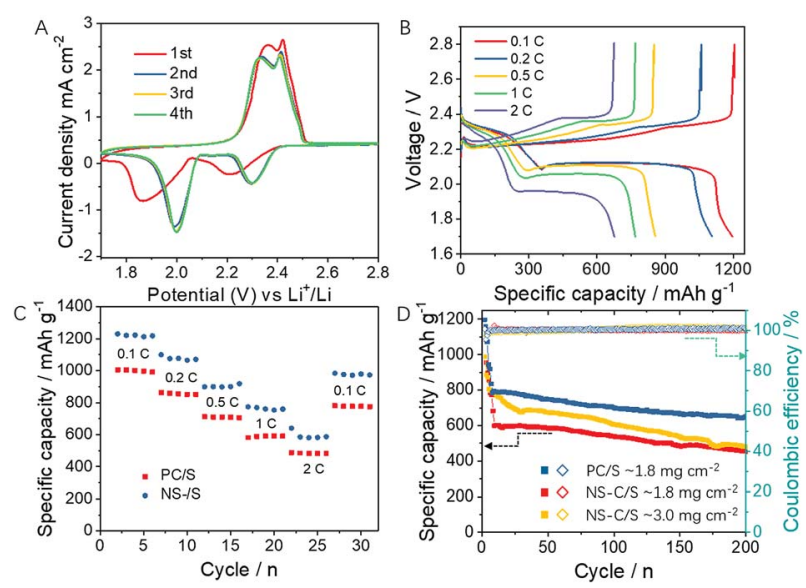

Fig. 4 Electrochemical performance of the different PCM-S composite. (A) CV curves of NS-C/S electrode. (B) Discharge-charge profiles of NS-C/S electrode from $0.1 \mathrm{C}$ to $2 \mathrm{C}$. (C) Rate capacity of sulfur electrodes at various current densities from $0.1 \mathrm{C}$ to $2 \mathrm{C}$. (D) Long cycling performance and coulombic efficiency of different sulfur electrodes at $1 \mathrm{C}$ for 200 cycles. 
of 2C (Fig. 4B and C). Meanwhile, the PC/S cathode showed much lower initial capacity ( $1003 \mathrm{~mA} \mathrm{~h} \mathrm{~g}^{-1}$ at $\left.0.1 \mathrm{C}\right)$ and less rate capability even with higher sulfur loading. After the working rate recovered from $2 \mathrm{C}$ to $0.1 \mathrm{C}, 80.6 \%$ capacity $\left(\sim 992 \mathrm{~mA} \mathrm{~h} \mathrm{~g}^{-1}\right)$ could be recovered relative to that of $77.3 \%$ ( $\sim 776 \mathrm{~mA} \mathrm{~h}^{-1}$ ) for the PC/S cathode, indicating the outstanding reversible capability of the NS-C/S cathode. The long-term cycling stability of these two cathodes was carried out at a $1 \mathrm{C}$ rate. After several activation cycles at $0.1 \mathrm{C}, \mathrm{NS}-\mathrm{C} / \mathrm{S}$ and $\mathrm{PC} / \mathrm{S}$ cathodes delivered initial discharge capacities of 815 and $776 \mathrm{~mA} \mathrm{~h} \mathrm{~g}^{-1}$ at $1 \mathrm{C}$, respectively. As shown in Fig. 4D, after 200 cycles, the PC/S cathode without heteroatom doping displayed noticeable capacity degradation to $456 \mathrm{~mA} \mathrm{~h} \mathrm{~g}{ }^{-1}$ (capacity retention of $58.7 \%$ ) while the NS-C/S cathode maintained a large capacity of $680 \mathrm{~mA} \mathrm{~h} \mathrm{~g}^{-1}$ (capacity retention of $83.4 \%$ ). Even after 500 cycles, the capacity of NS-C/S cathode still reached $\sim 550 \mathrm{~mA} \mathrm{~h} \mathrm{~g}{ }^{-1}$, showing nearly $70 \%$ capacity can be retained, confirming the excellent cycling stability of the NS-C/S cathode (Fig. S7 $\dagger$ ). The significantly improved cycling performance of the sulfur cathode can be attributed to both the physical confinement of the rich hierarchical porosity and chemical absorption by heavily involved heteroatom species. To further demonstrate the potentials of the PVC-converted NS-C in the practical Li-S battery, NS-C/S with the mass loading of $5.0 \mathrm{mg} \mathrm{cm}^{-2}$ was also fabricated into the cathode. A large specific capacity of $1013 \mathrm{~mA} \mathrm{~h} \mathrm{~g}^{-1}$ could still be delivered at $0.1 \mathrm{C}$ and $612 \mathrm{~mA} \mathrm{~h} \mathrm{~g}^{-1}$ at $1.0 \mathrm{C}$. After 200 cycles at $1.0 \mathrm{C}$, capacity retention as high as $79.4 \%\left(\sim 486 \mathrm{~mA} \mathrm{~h} \mathrm{~g}^{-1}\right)$ was maintained. Compared with other studies, the high sulfur loading capacity and outstanding LiPS trapping ability were confirmed in the plastic waste derived carbons with $\mathrm{N}$ and $\mathrm{S}$ heteroatoms doping. The merits could be attributed to the exquisite structure design and special synthesis approach. (1) Plastics dissolved in DMF solution increased the reaction surface; (2) $\mathrm{KOH}$ as the activating agent facilitated the creation of multi-pores; (3) high temperature calcination improved the degree of graphitization, contributing to good electrical conductivity; (4) the N, S heteroatoms doping increased the entrapping ability of soluble sulfur species.

\section{Conclusion}

In summary, hierarchically porous $\mathrm{N}, \mathrm{S}$ co-doped carbon materials were obtained through simple treatment of widely available PVC with $\mathrm{KOH}$ in the presence of thiourea, which possessed abundant porosity with large SSA of $808 \mathrm{~m}^{2} \mathrm{~g}^{-1}$ and rich heteroatom $\mathrm{N}$ and $\mathrm{S}$ doping, respectively reaching 6.5 at\% and 7.2 at\%. The NS-C was revealed to be capable of efficiently trapping soluble lithium polysulfides through the physical confinement of hierarchical pores and chemical absorption of $\mathrm{N}, \mathrm{S}$ species, which can be of great help for the improvement of the reversible capacity, rate and cycling performance of $\mathrm{Li}-\mathrm{S}$ batteries. Remarkably, the NS-C with sulfur loading of $1.8 \mathrm{mg}$ $\mathrm{cm}^{-2}$ can deliver a specific capacity as high as $\sim 1230 \mathrm{~mA} \mathrm{~h} \mathrm{~g}^{-1}$ at $0.1 \mathrm{C}$ and remain $\sim 815 \mathrm{~mA} \mathrm{~h} \mathrm{~g}^{-1}$ at $1 \mathrm{C}$. After 200 cycles at $1 \mathrm{C}$, the NS-C/S cathode can still keep a high capacity of $680 \mathrm{~mA} \mathrm{~h} \mathrm{~g}{ }^{-1}$ ( $\sim 84 \%$ capacity retention). Meanwhile, similar high capacity retention of $\sim 80 \%$ can be obtained even using higher sulfur loading. Our study features a low-cost, environmentally benign approach for the clean disposal and valueadded reuse of PVC plastic wastes that are largely accumulated on our planet. Meanwhile, it may also provide a feasible route to the near industrialization of $\mathrm{Li}-\mathrm{S}$ batteries.

\section{Conflicts of interest}

The authors declare no competing financial interest.

\section{Acknowledgements}

This study was supported by the Natural Science Foundation of China, the National Key Research and Development Project (2016YFF0204402), the National Natural Science Foundation of China $(21771018,21701101)$, Beijing University of Chemical Technology (start-up grant, BUCT, China), the Shandong Scientific Research Awards Foundation for Outstanding Young Scientists (ZR2018JL010), the Program for Changjiang Scholars and Innovative Research Team in the University, the Fundamental Research Funds for the Central Universities, and the Long Term Subsidy Mechanism from the Ministry of Finance and the Ministry of Education of PRC.

\section{References}

1 P. G. Bruce, S. A. Freunberger, L. J. Hardwick and J. M. Tarascon, Nat. Mater., 2011, 11, 19-29.

2 J. Zhang, H. Huang, J. Bae, S.-H. Chung, W. Zhang, A. Manthiram and G. Yu, Small Methods, 2018, 2, 1700279.

3 Y. X. Yin, S. Xin, Y. G. Guo and L. J. Wan, Angew. Chem., Int. Ed. Engl., 2013, 52, 13186-13200.

4 C. Zu and A. Manthiram, Adv. Energy Mater., 2013, 3, 10081012.

5 L. Ji, M. Rao, H. Zheng, L. Zhang, Y. Li, W. Duan, J. Guo, E. J. Cairns and Y. Zhang, J. Am. Chem. Soc., 2011, 133, 18522-18525.

6 Z. Li, L. Yuan, Z. Yi, Y. Sun, Y. Liu, Y. Jiang, Y. Shen, Y. Xin, Z. Zhang and Y. Huang, Adv. Energy Mater., 2014, 4, 1301473.

7 X. Ye, J. Ma, Y.-S. Hu, H. Wei and F. Ye, J. Mater. Chem. A, 2016, 4, 775-780.

8 W. Zhou, B. Guo, H. Gao and J. B. Goodenough, Adv. Energy Mater., 2016, 6, 1502059.

9 S. Lu, Y. Cheng, X. Wu and J. Liu, Nano Lett., 2013, 13, 24852489.

10 R. Fang, S. Zhao, P. Hou, M. Cheng, S. Wang, H. M. Cheng, C. Liu and F. Li, Adv. Mater., 2016, 28, 3374-3382.

11 D.-W. Wang, Q. Zeng, G. Zhou, L. Yin, F. Li, H.-M. Cheng, I. R. Gentle and G. Q. M. Lu, J. Mater. Chem. A, 2013, 1, 9382. 12 R. Fang, C. Liang, Y. Xia, Z. Xiao, H. Huang, Y. Gan, J. Zhang, X. Tao and W. Zhang, J. Mater. Chem. A, 2018, 6, 212-222.

13 L. Zeng, F. Pan, W. Li, Y. Jiang, X. Zhong and Y. Yu, Nanoscale, 2014, 6, 9579-9587.

14 Y. Xia, H. Zhong, R. Fang, C. Liang, Z. Xiao, H. Huang, Y. Gan, J. Zhang, X. Tao and W. Zhang, J. Power Sources, 2018, 378, 73-80. 
15 C. Xu, Y. Wu, X. Zhao, X. Wang, G. Du, J. Zhang and J. Tu, J. Power Sources, 2015, 275, 22-25.

16 W. Deng, X. Zhou, Q. Fang and Z. Liu, J. Mater. Chem. A, 2017, 5, 13674-13682.

17 X.-B. Cheng, J.-Q. Huang, Q. Zhang, H.-J. Peng, M.-Q. Zhao and F. Wei, Nano Energy, 2014, 4, 65-72.

18 R. Singhal, S.-H. Chung, A. Manthiram and V. Kalra, J. Mater. Chem. A, 2015, 3, 4530-4538.

19 J. Zhang, H. Zhong, C. Zheng, Y. Xia, C. Liang, H. Huang, Y. Gan, X. Tao and W. Zhang, J. Power Sources, 2018, 391, 73-79.

20 Z. Yuan, H. J. Peng, T. Z. Hou, J. Q. Huang, C. M. Chen, D. W. Wang, X. B. Cheng, F. Wei and Q. Zhang, Nano Lett., 2016, 16, 519-527.

21 J. Zhang, Y. Shi, Y. Ding, W. Zhang and G. Yu, Nano Lett., 2016, 16, 7276-7281.

22 H. Li, Y. Tao, C. Zhang, D. Liu, J. Luo, W. Fan, Y. Xu, Y. Li, C. You, Z.-Z. Pan, M. Ye, Z. Chen, Z. Dong, D.-W. Wang, F. Kang, J. Lu and Q.-H. Yang, Adv. Energy Mater., 2018, 1703438.

23 F. Pei, L. Lin, D. Ou, Z. Zheng, S. Mo, X. Fang and N. Zheng, Nat. Commun., 2017, 8, 482.

24 P. Zhu, J. Zhu, J. Zang, C. Chen, Y. Lu, M. Jiang, C. Yan, M. Dirican, R. Kalai Selvan and X. Zhang, J. Mater. Chem. A, 2017, 5, 15096-15104.

25 Y. Jiang, H. Liu, X. Tan, L. Guo, J. Zhang, S. Liu, Y. Guo, J. Zhang, H. Wang and W. Chu, ACS Appl. Mater. Interfaces, 2017, 9, 25239-25249.

26 K. Mi, S. Chen, B. Xi, S. Kai, Y. Jiang, J. Feng, Y. Qian and S. Xiong, Adv. Funct. Mater., 2017, 27, 1604265.

27 Q. Wang, Z.-B. Wang, M. Yang, C. Li and D.-M. Gu, J. Mater. Chem. A, 2017, 5, 16796-16802.

28 X. Ji, K. T. Lee and L. F. Nazar, Nat. Mater., 2009, 8, 500-506.

29 W. Zhou, X. Xiao, M. Cai and L. Yang, Nano Lett., 2014, 14, 5250-5256.

30 S. Liang, C. Liang, Y. Xia, H. Xu, H. Huang, X. Tao, Y. Gan and W. Zhang, J. Power Sources, 2016, 306, 200-207.

31 Z. Peng, W. Fang, H. Zhao, J. Fang, H. Cheng, T. N. L. Doan, J. Xu and P. Chen, J. Power Sources, 2015, 282, 70-78.

32 S.-R. Chen, Y.-P. Zhai, G.-L. Xu, Y.-X. Jiang, D.-Y. Zhao, J.-T. Li, L. Huang and S.-G. Sun, Electrochim. Acta, 2011, 56, 9549-9555.

33 Y. Xia, R. Fang, Z. Xiao, H. Huang, Y. Gan, R. Yan, X. Lu, C. Liang, J. Zhang, X. Tao and W. Zhang, ACS Appl. Mater. Interfaces, 2017, 9, 23782-23791.

34 J. Zhang, Y. Shi, Y. Ding, L. Peng, W. Zhang and G. Yu, Adv. Energy Mater., 2017, 7, 1602876.

35 F. Pei, L. Lin, A. Fu, S. Mo, D. Ou, X. Fang and N. Zheng, Joule, 2018, 2, 323-336.

36 M. Wang, W. Wang, A. Wang, K. Yuan, L. Miao, X. Zhang, Y. Huang, Z. Yu and J. Qiu, Chem. Commun., 2013, 49, 10263-10265.
37 A. K. Panda, R. K. Singh and D. K. Mishra, Renewable Sustainable Energy Rev., 2010, 14, 233-248.

38 G. Zhang, L. Wang, Y. Hao, X. Jin, Y. Xu, Y. Kuang, L. Dai and X. Sun, Adv. Funct. Mater., 2016, 26, 3340-3348.

39 C. Hu, G. Zhang, H. Li, C. Zhang, Y. Chang, Z. Chang and X. Sun, RSC Adv., 2017, 7, 22071-22078.

40 G. Zhang, J. Wang, B. Qin, X. Jin, L. Wang, Y. Li and X. Sun, Carbon, 2017, 115, 28-33.

41 C. Zhang, G. Zhang, H. Li, Y. Chang, Z. Chang, J. Liu and X. Sun, Electrochim. Acta, 2017, 247, 1044-1051.

42 Y. Qu, Z. Zhang, X. Wang, Y. Lai, Y. Liu and J. Li, J. Mater. Chem. A, 2013, 1, 14306.

43 S. Ratso, I. Kruusenberg, M. Käärik, M. Kook, R. Saar, M. Pärs, J. Leis and K. Tammeveski, Carbon, 2017, 113, 159-169.

44 J. Li, J. Xu, Z. Xie, X. Gao, J. Zhou, Y. Xiong, C. Chen, J. Zhang and Z. Liu, Adv. Mater., 2018, 30, e1800548.

45 A. C. Ferrari and D. M. Basko, Nat. Nanotechnol., 2013, 8, 235-246.

46 F. Xu, Z. Tang, S. Huang, L. Chen, Y. Liang, W. Mai, H. Zhong, R. Fu and D. Wu, Nat. Commun., 2015, 6, 7221.

47 D. Li, F. Han, S. Wang, F. Cheng, Q. Sun and W. C. Li, ACS Appl. Mater. Interfaces, 2013, 5, 2208-2213.

48 D. Sun, R. Ban, P.-H. Zhang, G.-H. Wu, J.-R. Zhang and J.-J. Zhu, Carbon, 2013, 64, 424-434.

49 G. Zhou, E. Paek, G. S. Hwang and A. Manthiram, Nat. Commun., 2015, 6, 7760.

50 M. Li, Y. Zhang, X. Wang, W. Ahn, G. Jiang, K. Feng, G. Lui and Z. Chen, Adv. Funct. Mater., 2016, 26, 8408-8417.

51 J. Zhao, W. Ren and H.-M. Cheng, J. Mater. Chem., 2012, 22, 20197.

52 R. Demir-Cakan, M. Morcrette, F. Nouar, C. Davoisne, T. Devic, D. Gonbeau, R. Dominko, C. Serre, G. Ferey and J. M. Tarascon, J. Am. Chem. Soc., 2011, 133, 16154-16160.

53 C. Zu, Y. Fu and A. Manthiram, J. Mater. Chem. A, 2013, 1, 10362.

54 X. Gu, C.-j. Tong, C. Lai, J. Qiu, X. Huang, W. Yang, B. Wen, L.-m. Liu, Y. Hou and S. Zhang, J. Mater. Chem. A, 2015, 3, 16670-16678.

55 H. Hu, H. Cheng, Z. Liu, G. Li, Q. Zhu and Y. Yu, Nano Lett., 2015, 15, 5116-5123.

56 Z. Xiao, Z. Yang, L. Zhou, L. Zhang and R. Wang, ACS Appl. Mater. Interfaces, 2017, 9, 18845-18855.

57 Y. Peng, B. Li, Y. Wang, X. He, J. Huang and J. Zhao, ACS Appl. Mater. Interfaces, 2017, 9, 4397-4403.

58 J. Q. Huang, T. Z. Zhuang, Q. Zhang, H. J. Peng, C. M. Chen and F. Wei, ACS Nano, 2015, 9, 3002-3011.

59 N. Jayaprakash, J. Shen, S. S. Moganty, A. Corona and L. A. Archer, Angew. Chem., Int. Ed. Engl., 2011, 50, 59045908.

60 Y. Zhong, D. Chao, S. Deng, J. Zhan, R. Fang, Y. Xia, Y. Wang, X. Wang, X. Xia and J. Tu, Adv. Funct. Mater., 2018, 1706391. 